\title{
Gender differences in adolescents' written texts
}

Georgia Andreou, Maria Liakou, Fotini Anastassiou, Vassiliki Tsela

Department of Special Education, University of Thessaly, Greece/ Hellenic Open

University, Greece

https://doi.org/10.36505/ExLing-2018/09/0003/000336

\begin{abstract}
The aim of this study was to compare adolescents' lexical abilities in relation to their gender, examining the differences between their age too. The study compared lexical abilities in written narrative and non-narrative texts of three hundred typically developed adolescents. The results showed performance differences between female and male participants, with a tendency of an advantage of females over males due to higher persistence and systematic effort levels on the part of the females.

Key words: Gender differences, lexical abilities, written texts, adolescence
\end{abstract}

\section{Introduction}

Gender differences are more evident in adolescence than in childhood. Such disparities have been attributed to the dissimilarities in the rate in which their brains mature. As it has been demonstrated, a girl's brain evolves psycho-motorically and it ultimately develops faster than a boy's. The faster maturation of girls means "lower final slanting, i.e. increased cerebral symmetry and increased verbal ability" (Andreou, 2012). Gender differences in their grading performance assume a pattern from around the age of 11 and remain consistent throughout schooling in secondary education (Berninger, Nielsen, Abbott, Wijsman \& Raskind, 2008; Voyer \& Voyer, 2014).

In the present study, criteria of lexical complexity were used in written texts of adolescents. Specifically, as far as lexical analysis is concerned we focused on the following two criteria: 1) Length of words (words with 3 or more syllables) (Berman, 2008; Berman \& Nir-Sagiv, 2007), i.e. words from three syllables and above, which is an indicator of advanced student development and an important criterion of vocabulary complexity; 2) The use of abstract nouns (Berman, 2008; Berman and Nir-Sagiv, 2007; Nippold, 2007), which is an advanced vocabulary index.

Finally, in the present study, we adopted the distinction between narrative and non-narrative texts in order to avoid the fragmentation of speech into unrelated categories without clear boundaries. Narrative texts are those that reflect specific experiences, mostly the ones that belong to the past, and those that put an emphasis on human actions and experiences. Non-narrative texts are more demanding because they focus

ExLing 2018: Proceedings of $9^{\text {th }}$ Tutorial and Research Workshop on Experimental Linguistics, 28-30 August, Paris, Frannce 
on a broad field of description or on the development of concepts, arguments and information without relying on narration (Georgakopoulou \& Goutsos, 1999). Adolescents must demonstrate their ability to write in a variety of texts. The text holds a key position in the whole curriculum of teaching language lessons since students are constantly being asked to recognize the type of texts and meet their demands.

\section{Purpose of the study}

Based on the above, the aim of this study was to compare adolescents' lexical abilities in relation to their age while examining the differences between the two genders. Given the difficulty of producing different types of written texts, it was also predicted that girls' writings will show a higher performance than boys' writings in both age groups but also in both types of texts.

\section{Method}

\section{Participants}

Our research took place in public, urban high schools in Greece. The sample consisted of two groups of 300 typically developing adolescents $(\mathrm{N}=300)$ whose average age was 14.5 ( $N=150$ early adolescents) and $16.6(\mathrm{~N}=150$ late adolescents) years old respectively.

\section{Procedure}

A text on racism was distributed to the students and they were asked to produce one non-narrative and one narrative text, following the instructions given. In total, this study analyzed 600 written texts, half of them being narrative and half non-narrative ones.

\section{Analysis}

The Mann-Whitney U Test was used to detect possible differences in written texts between early and late adolescents. It is the non-parametric alternative to the independent t-test. SPSS 15 was used for our statistical analysis and Monte Carlo simulation methods were used to obtain the pvalue. When the $\mathrm{p}$-value is less than the significance level $\alpha(a=0.05)$, the result is said to be statistically significant.

\section{Results}

The statistical analysis of Mann-Whitney (see tables 1,2) revealed that there is a statistically significant difference in narrative texts between the 
two groups of adolescents (boys vs girls) in the: a) length of words (words with 3 or more syllables) and b) abstract nouns.

Table 1. Mean percentage of length of words (words with 3 or more syllables) and abstract nouns by gender (boys vs. girls- early adolescents) in narrative texts (S: Significant - NS: Non Significant).

\begin{tabular}{|l|l|l|}
\hline \hline Type of Adolescents & Length of words & Abstract nouns \\
\hline Boys (early adolescents) & 37.1 & 1.6 \\
\hline Girls (early adolescents) & 41.7 & 2.4 \\
\hline p-value & $0.216(\mathrm{NS})$ & $0.030(\mathrm{~S})$ \\
\hline
\end{tabular}

Table 2. Mean percentage of length of words (words with 3 or more syllables) and abstract nouns by gender (boys vs. girls- late adolescents) in narrative texts (S: Significant - NS: Non Significant).

\begin{tabular}{|l|l|l|}
\hline \hline Type of Adolescents & Length of words & Abstract nouns \\
\hline Boys (late adolescents) & 43.4 & 2.1 \\
\hline Girls (late adolescents) & 47.6 & 2.0 \\
\hline p-value & $0.063(\mathrm{NS})$ & $\mathrm{p}=0.572(\mathrm{NS})$ \\
\hline \hline
\end{tabular}

Also, the statistical analysis of Mann-Whitney (see tables 3, 4) showed a statistically significant difference in non-narrative texts between the two genders in the: a) length of words (words with 3 or more syllables) and b) abstract nouns.

Table 3. Mean percentage of length of words (words with 3 or more syllables) and abstract nouns in terms of gender (boys vs. girls- early adolescents) in non-narrative texts (S: Significant - NS: Non Significant).

\begin{tabular}{|l|l|l|}
\hline \hline Type of Adolescents & Length of words & Abstract nouns \\
\hline Boys (early adolescents) & 41.5 & 3.3 \\
\hline Girls (early adolescents) & 49.7 & 6.4 \\
\hline p-value & $0.010(\mathrm{~S})$ & $<0.001(\mathrm{~S})$ \\
\hline
\end{tabular}

Table 4. Mean percentage of length of words (words with 3 or more syllables) and abstract nouns in terms of gender (boys vs. girls- late adolescents) in non-narrative texts (S: Significant - NS: Non Significant).

\begin{tabular}{|l|l|l|}
\hline Type of Adolescents & Length of words & Abstract nouns \\
\hline Boys (late adolescents) & 44.8 & 4.5 \\
\hline Girls (late adolescents) & 57.0 & 5.4 \\
\hline p-value & $<0.001(\mathrm{~S})$ & $0.110(\mathrm{NS})$ \\
\hline
\end{tabular}




\section{Discussion - Conclusions}

Gender analysis revealed that girls showed better performance than boys, and so the initial hypothesis was confirmed. Indeed, in several cases these differences were statistically significant, while in others the differences were within the limits of statistical significance. The findings above, in the age comparison, showed that in almost all the lexical criteria girls are superior to the boys in both types of texts.

In conclusion, gender differences are more evident in adolescence than in childhood. Gender differences in the production of written texts have been observed in this study. In most research, this particular finding is common, that is, girls have a higher degree of linguistic proficiency than boys. The written texts of girls systematically outweighed the boys and the difference was greater in the theoretical-language lessons (as here is the production of written text) in relation to applied sciences and mathematics (Berninger et al., 2008; Voyer \& Voyer, 2014). In addition, this is an indication that girls may have encountered less difficulty in producing texts or that they may have tried more than the boys or that they may have been more focused on the language part of the research. Therefore, the relationship between gender and lexical skills has shown differences between the two genders, given that that girls tended to outperform boys because of their more persistent and systematic effort.

\section{References}

Andreou, G. 2012. Language: Theoretical and Methodological Approach (3rd edition), Athens: Pedio Publications.

Berman, R.A. 2008. The psycholinguistics of developing text construction. Journal of Child Language 35, 735-771.

Berman, R.A., Nir-Sagiv, B. 2007. Comparing narrative and expository text construction across adolescence: A developmental paradox. Discourse Processes 43 (2), 79-120.

Berninger, V.W., Nielsen, K.H., Abbott, R.D., Wijsman, E., Raskind, W. 2008. Gender differences in severity of writing and reading disabilities. Journal of School Psychology 46, 151-172.

Georgakopoulou, A., Goutsos, D. 1999. Text and Communication. Athens: Ellinika Grammata.

Nippold, M. 2007. Later Language Development: School-Age Children, Adolescents, and Young Adults. Austin, TX, Pro-Ed.

Nippold, M.A., Hegel, S.L., Sohlberg, M.M., Schwarz, I.E. 1999. Defining Abstract Entities: Development in Pre-Adolescents, Adolescents, and Young Adults. Journal of Speech, Language, and Hearing Research 42, 473-481.

Voyer, D., Voyer, S.D. 2014. Gender Differences in Scholastic Achievement: A MetaAnalysis. Psychological Bulletin 140 (4), 1174-1204. 